\title{
PENGARUH KEPEMIMPINAN, LINGKUNGAN KERJA, DISIPLIN \\ KERJA DAN MOTIVASI KERJA TERHADAP KINERJA \\ KARYAWAN DINAS PETERNAKAN DAN PERIKANAN \\ KABUPATEN GROBOGAN
}

\author{
Setyo Wahyuningsih ${ }^{1}$ \\ Sudarmadi $^{2}$ \\ Triyanto ${ }^{3}$ \\ 1,2,3 Program Studi Manajemen STIE Atma Bhakti Surakarta \\ Email: sudarmadi60@gmail.com
}

\begin{abstract}
This study purposes were determined the effect of leadership, work environment, work discipline and motivation on employee performance at the Dinas Peternakan dan Perikanan, Grobogan Regency. The research type is a survey research using a questionnaire as the instrument. The research population are employees at the Dinas Peternakan dan Perikanan, Grobogan Regency. The sample used in this study amounted to 62 respondents. Data collection technique used questionnaire that has been tested for validity and reliability. The data analysis technique used is multiple linear regression. The research results shown that there is a positive and significant effect of leadership, work environment, work discipline, and work motivation on employee performance both individually and simultaneously. Leadership is the variable with the most dominant effect on the performance of the employees of the Dinas Peternakan dan Perikanan in Grobogan Regency.
\end{abstract}

Keywords: leadership, work environment, work discipline, work motivation, employee performance

\section{PENDAHULUAN}

Pegawai Negeri Sipil memiliki kedudunan dan peran sebagai aparat negara yang memiliki kewajiban sebagaiu abdi masyarakat dalam melaksanakan pelayakan harus dilakukan dengan adil dengan didasari pada ketaatan pada Pancasila dan UUD 1945. Peningkatan kinerja pegawai dapat dilaksanakan melalu kegiatan pembinaan pegawai yang bertujun meningkatkan mutu sumber daya manusia agar pegawai memiliki perilaku an sikap yang memiliki jiwa mengabdi, jujur, bertanggung jawab, disiplin tinggi dan berwibawa sehingga pelayanan yang diberikan kepada masyarakat sesuai dengan apa yang sudah diatur dan sesuai dengan keinginan masyarakat.

Kinerja pegawai adalah faktor penting dalam pencapaian visi dan misi organisasi atau lembaga, dengan demikian kinerja pegawai harus selalu 
ditingkatkan. Faktor yang menentukan tersebut antara lain: 1) Faktor personal, antara lain kepercayaan diri, pengetahuan, dan tersedianya dukungan terhadap peningkatan kinerja pegawai; 2) Faktor tim, antara lain dukungan dan motivasi dari sesama teman dalam satu tim, kebersamaan dalam tim, saling percaya terhadap anggota tim, dan keakraban sesama anggota tim; 3) faktor sistem, antara lain sistem kerja, fasilita di tempat kerja, sarana prasarana yang disediakan lembaga, kompensasi, alur kerja organisasi, dan budaya kerja organisasi; 4) Faktor kontekstual, antara lain semangan kerja (motivasi) dan komitmen pegawai terhadap organisasi dan pekerjaan; 5) Faktor pemimpin, antara lain kualitas manajemen dan pimpinan tim dalam mendorong dan memberikan motivasi kepada bawahan, serta adanya perubahan kondisi lingkungan iternal dan eksternal.

Salah satu hal yang harus diperhatikan oleh lembaga atau organisasi yang berhubungan dengan SDM adalah faktor kepemimpinan. Kepemimpinan merupakan kepandaian seseorang untuk mempengaruhi orang lain untuk berupaya mencapai tujuan organisasi atau lembaga secara sungguh-sungiuh. Pemimpin adalah orang yang berwenang untuk membagi tugas, mmpu untuk mempengaruhi pegawia atau anggota organisasi lain melalui pola hubungan yang kut untuk mendorong pencapaian tujuan organisasi yang ditetapkan sebelumnya. Fikri Djafar Fadude, Hendra N Tawas, Jane Grace Poluan (2019), Alwi Suddin, Sudarman (2010) dan Maria Rini Kustrianingsih, Maria Magdalena Minasrsih, Leonardo Budi Hasiolan(2016) menunjukan bahwa sikap pemimpin (kepemimpinan) memiliki dampak baik pada kinerja karyawan.

\section{KAJIAN PUSTAKA DAN PENGEMBANGAN HIPOTESIS}

Lingkungan kerja sangat mendukung keberhasilan suatu perusahaan. Lingkungann kerja adalah kondisi yang ada di sekitar lokasi pekerjaan baik berupa fisik atau non fisik yang mampu memberikan mafaat yang menyebabkan senang, aman, dan tentram. Lingkunga kerja yang teppat menyebabkan pegawai menjadi tenang dalam bekerja. Perasaaan nyaman dalam bekerja akan mampu meningkatkan kinerja pegawai. Seperti penelitian terdahunu oleh Joyce Sagita Novyanti (2015), Alwi Suddin, Sudarman (2010), Heny Sidanti (2015) dan Asta 
Wijayan, Alwi Suddin, SL Triyaningsih (2016) menyatakan bahwa lingkungan kerja memiliki dampak yang baik pada kinerja pegawai.

Guna semakin menaikkan kinerja pegawai, organisasi melakukan upaya peningkatan disiplin pegawai. Disiplin kerja adalah sikap atau perilaku yang harus dimiliki pegawai dalam organisasi atau perusahaan untuk menaikkan kinerja sehingga tujuan organisasi atau perusahaan dapat dicapai secara optimal. Penelitian terdahulu oleh Joyce Sagita Noviyanti (2015), Heny Sidanti(2015), menyatakan bahwa disiplin kerja memiliki pengaruh baik pada kinerja karyawan.

Untuk mencapai kinerja unggul, selain diperlukan disiplin kerja setiap karyawan perlu memiliki motivasi kerja. Motivasi kerja adalah peralatan yang dimanfaat oleh pemimpin guna melakukan komunikasi dengan pegawai supaya pegawai tersebut mau untuk mengubah sikap. Motivasi juga merupakan usaha untuk meninggikan kesadaran dan kemauan seorang pegawai dalam upaya untuk mematuhi aturan organiasi atau perusahaan.Penelitian terdahulu oleh Joyce Sagita Noviyanti(2015), Alwi Suddin, Sudarman (2010), Heny Sidanti(2015), Natalia Susanto(2019) dan Maria Rini Kustrianingsih, Maria Magdalena Minarsih, Leonardo Budi Hasiolan (2016) menyatakan bahwa motivasi kerja memiliki pengaruh nyata pada kinerja pegawai.

\section{METODE PENELITIAN}

\section{Jenis Penelitian}

Penelitian ini termasuk ke dalam explanatory research. Menurut Singarimbun dan Efendi (195:5) explanatory research merupakan suatu studi yang berupaya memberi penjelasan mengenai keterkaitan antara variabelvariabel melalui pengujian hipotesis. Tujuan studi ini adalah untuk mencari pengaruh antara variabel bebas yaitu kepemimpinan, disipklin, lingkungan, dan motivasi. Studi ini menerapkan pendekatan kuantitatif deskriptif karena data yang disajikan berupa angka dan menggunakan anlisis deskriptif. 


\section{Tempat dan Waktu Penelitian}

Penelitian ini diselenggarakan di Kantor Dinas Peternakan dan Perikanan Kabupaten Grobogan yang beralamatkan di Jalan A. Yani No. 118 Purwodadi - Grobogan pada bulan Juni 2020.

\section{Variabel Peneltian}

Variabel penelitian meruakan suatu organ atau bagian dari subyek atau obyek yang mempunyai ragam khusus yang telah ditentukan peneliti untuk diteliti serta dibuat kesimpulan seperti halnya pendapat Sugiyono (2008) yang dikutip oleh Purba (2012:63). Pada penelitian ini, variabel penelitian terdiri atas variabel dependen (variabel terikat) dan variabel independen (variabel bebas). Variabel dependen penelitian ini adalah: Kinerja Karyawan (Y). Variabel independen antara lain: Kepemipinan (X1), Lingkunngan Kerja (X2), Dissiplin Kerja (X3), dan Motivasi Kerja (X4).

\section{Jenis Data}

Data penelitian termasuk jeni data primer, dalam pengumpulan data primer tersebut, peneliti membuat kuesioner dimana peneliti mengajukan beberapa daftar pertanyaan terhadap karyawan Dinas Peternakan dan Perikanan Kab. Grobogan. Data sekunder adalah salah satu jenis data penelitian yang didapatkan melalui cara yang tidak langsung atau menggunakan perantara tertentu. Data ini sudah tersedia, sehingga peneliti hanya mencari dan mengumpulkan saja. Data primer didapatkan secara langsung dari lokasi peelitian sedangkan data sekunder yang diperoleh melalui kepustakaan, literature, dan jurnal.

\section{Populasi Dan Sampel}

Populasi penelitian merupakan semua karyawan Dinas Peternakan dan Perikanan Kab. Grobogan yang berjumlah sebanyak 62 orang. Cara pengambilan sampel dilaksanakan dengan metode Non Probability Sampling. Non Probability Sampling adalah suatu cara pengambila jumlah sampel yang dipiloih dengan cara tidak acak. Dalam penelitian ini sampel yang akan diambil adalah seluruh karyawan Dinaas Peternaakan dan Perikanan Kab. Grobogan yaitu sebanyak 62 orang sebagai responden. 


\section{Teknik Pengumpulan Data}

Teknik pengumpulan data penelitian menggunakan metode antara lain questioner, interview (wawancara), dan observasi.

\section{Metode Analisi Data}

Analisis data kuantitatif merupakan data dalam bentuk angka yang didapatkan untuk menjelaskan suatu hubungan dari angka tersebut atau melakukan perbandingan dari sesuatu sehingga diperoleh gambaran baru, selanjutnya diterangkan dalam kalimat/uraian. Pada penelitian ini data akan diolah menggu menggunakan software computer yaitu SPSS (Statstical Package for Social Sciense) yang berguna untuk melakukan analisis data, melakukan opertmbangan statistik baik untuk statistik parametrik maupun non parametrik. Dalam penelitian ini digunakan program SPSS versi 22.

\section{Pengujian Instrumen}

Pengujian instrumen penelitian dilaksanakan mengan validitas dan reliabilitas Tujuan dari uji validtas dan reliabilias adalah menguji setiap item pernuataan pada kuesioner, apakah isi dari butir-butir ertanyaan tersebut telah valid dan realiabel. Pada pengujian validitas ini memakai metode korelasi product moment oleh pearson. Uji reliabilitas dapat diukur secara bersamasama terhadap seluruh butir pertanyaan. Jika nilai alpha $>0,6$ maka reliable, dan sebaliknya apabila nilai alpha $<0,6$ berarti tidak reliable.

\section{Uji Asumsi Klasik}

Pengujian asumi klasik sebagai prayarat analisis terdiri atas uji normalitas, uji multikolonieritas, uji heteroskedastisitas, dan uji autokorelasi. Normalitas data diuji dengan menerapkan metode One Sample Kolmogorov Smirnov. Multikolinearitas data hasil penelitian diuji melalui nilai toleransi dan besarnya Variance Inflation Factor. Heteroskedastisitas data penelitian dites melalui grafik scatterplot. Uji autokorelasi menggunaan uji DorbinWatson.

\section{Uji Hipotesis}

Pengujian hipotesis menggunakan teknik antara lain Regressi Linier Berganda, Tes Parsial (Uji t), Tes Simultan (Uji F), dan Uji Koefisien Determinan $\left(\mathrm{R}^{2}\right)$. Uji regressi linier berganda diterapkan guna menentukan 
pengaruh variabel penelitian yang terdiri dari beberapa variabel bebas dan satu variabel terikat. Uji parsial atau biasa disebut Uji t merupakan uji yang dilakukan dalam menentukan pengaruh setiap variabel, antara lain variabel independen (bebas) terhadap variabel terikat. Pengujian ini dilakukan dengan deraat kepercayaan $95 \%$ dan derajat kebebasan (alpha) 5\% dengan $d f=\alpha / 2$; (n-k-1).

Uji F merupakan pengujia yang dilksanakan guna mengetahui semua variabel independen $(\mathrm{X})$ memiliki pengaruh terhadap dependen $(\mathrm{Y})$ secara bersama-sama. Uji F dislaksanakan guna menguji pengaruh secara simultan atau bersama-sama variabel bebas terhadap variabell terikat. Pengujian dilaksanakan melalui metode uji $\mathrm{F}$ dengan derajat keyakinan 95\% dan tingkat kesalahan analisa $(\alpha)=5 \%$.

Koefisien determinasi dilaksanakan untuk menentukan besarnya kemampuan variabel bebas untuk menjelaskan variabel terikat. Koefisien determinasi $\left(\mathrm{R}^{2}\right)$ lebih menjelaskan pada kesanggupan variabel bebas $(\mathrm{X})$ untuk menjelaskan variabel terikat $(Y)$. Nilai koefisien determinasi $\left(R^{2}\right)$ adalah 0 (nol) sampai dengan 1 (satu), dimana nilai $\mathrm{R}^{2}$ yang kecil atau mendekati nol berarti kemampuan variabel-varaibel independennya dalam menjelaskan variebel-variabel dependen sangat terbatas.

\section{HASIL DAN PEMBAHASAN}

\section{Pengujian Instrumen}

\section{a. Uji Validitas}

Hasil perhitungan uji validitas terhadap kuesioner menunjukkan bahwa seluruh butir kuesioner valid karena nilai $\mathrm{r}_{\mathrm{xy}}$ lebih tinggi daripada $r_{\text {tabel }}$ dalam taraf signifikansi $(\alpha)=5 \%$ adalah 0,254 sehingga tiap item pertanyaan dinyatakan valid (sahih). Artinya tiap item pernyataan dapat dipercaya untuk mengambil data penelitian.

\section{b. Uji Reliabilitas}

Hasil uji reliabilitas terhadap kuesioner memperoleh koefisien reliabilitas $\left(r_{11}\right)$ yang bergerak dari 0,807 hingga 0,706 , dimana seluruh 
nilai tersebut lebih banyak daripoada 0,6 maka realible, dan sebaliknya apabila nilai alpha 1; ebih sedikit dari 0,6 diartikan tidak reliable (Priyatno: 120), maka dapat dikatakan semua kuesioner yang dimasukkan untuk penelitian adalah reliable (andal). Artinya seluruh kuesioner dapat dipercaya dan mampu untuk menjadi alat pengumpul data.

\section{Uji Asumsi Klasik}

\section{a. Uji Normalitas}

Uji normalitas dilakukan dengan metode grafik, yaitu dengan cara melibat pesebaran data pada bidang diagonal pada grafik Normal P-P Pot of Regression Standardized Residual. Dasar pengambilan simpulan hasil analisis adalah apabila titik-tituik tersbar di sekitar garis diagonal maka data tersebut dikatakan normal.

\section{b. Uji Multikolinieritas}

Uji multikolinieritas dimaksudkan untuk menentukan ada tidaknya korelasi diantara variabel bebas dalam penelitian. Persyaratan uji ditampilkan dari Variance Inflation Factor (VIF) dan nilai Tolerance Value. Hasil tes multikolinieritas secara ringkas ditunjukkan dalam tabel 1.

Tabel 1

Hasil Uji Multikolinieritas

Coefficients $^{\mathrm{a}}$

\begin{tabular}{|c|c|c|c|c|c|c|c|c|}
\hline \multirow{2}{*}{\multicolumn{2}{|c|}{ Model }} & \multicolumn{2}{|c|}{$\begin{array}{l}\text { Unstandardized } \\
\text { Coefficients }\end{array}$} & \multirow{2}{*}{$\begin{array}{c}\begin{array}{c}\text { Standardize } \\
\mathrm{d} \\
\text { Coefficients }\end{array} \\
\text { Beta }\end{array}$} & \multirow[b]{2}{*}{$\mathrm{T}$} & \multirow[b]{2}{*}{ Sig. } & \multicolumn{2}{|c|}{$\begin{array}{l}\text { Collinearity } \\
\text { Statistics }\end{array}$} \\
\hline & & B & $\begin{array}{l}\text { Std. } \\
\text { Error }\end{array}$ & & & & $\begin{array}{c}\text { Toleran } \\
\text { ce }\end{array}$ & VIF \\
\hline & (Constant) & -4.084 & 3.162 & & -1.292 & .202 & & \\
\hline & $\mathrm{X} 1$ & .428 & .095 & .405 & 4.487 & .000 & .804 & 1.243 \\
\hline & $\mathrm{X} 2$ & .254 & .094 & .253 & 2.712 & .009 & .754 & 1.326 \\
\hline & $\mathrm{X} 3$ & .239 & .119 & .198 & 2.011 & .049 & .673 & 1.485 \\
\hline & $\mathrm{X} 4$ & .230 & .091 & .254 & 2.523 & .014 & .645 & 1.550 \\
\hline
\end{tabular}

a. Dependent Variable: Y

Sumber: Data primer diolah, 2020

Hasil uji di atas tampak bahwa nilai tolerance seluruh variabel lebih besardari 0,1 , sedangnn nilai VIF tampak bahwa seluruhnya lebih kecil dari 10, sehingga dapat diinterpretasikan bahwa data variabel penelitian tidak ada yang menunjukkan tanda-tanda multikolineritas dalam model regresinya. 


\section{c. Uji Heteroskedastisitas}

Uji heteroskedastisitas dilaksanakan untuk menetukan ada tidaknya ketidaksamaan dalam model regresi. Apabila terjadi varian dari suatu data observasi ke ovbservasi yang lainnya tetap, maka dinamakan homokedastisitas. Sehingga dapat diinterpretasikan tidak ada masalah heterokedastisitas.Untuk menegaskan hasil uji heterokedastisitas selanjutnya dilaksanakan uji glejser seperti ditinjukkan di bawah ini

Tabel 2

Hasil Uji Heteroskedastisitas

Coefficients $^{\mathrm{a}}$

\begin{tabular}{|c|c|c|c|c|c|c|c|c|}
\hline & \multirow{2}{*}{ Model } & \multicolumn{2}{|c|}{$\begin{array}{l}\text { Unstandardized } \\
\text { Coefficients }\end{array}$} & \multirow{2}{*}{$\begin{array}{c}\begin{array}{c}\text { Standardized } \\
\text { Coefficients }\end{array} \\
\text { Beta }\end{array}$} & \multirow{2}{*}{$\mathbf{T}$} & \multirow{2}{*}{ Sig. } & \multicolumn{2}{|c|}{$\begin{array}{c}\text { Collinearity } \\
\text { Statistics }\end{array}$} \\
\hline & & B & $\begin{array}{l}\text { Std. } \\
\text { Error }\end{array}$ & & & & $\begin{array}{c}\text { Toleran } \\
\text { ce }\end{array}$ & VIF \\
\hline \multirow{5}{*}{1} & (Constant) & -4.084 & 3.162 & & -1.292 & .202 & & \\
\hline & $\mathrm{X} 1$ & .428 & .095 & .405 & 4.487 & .000 & .804 & 1.243 \\
\hline & $\mathrm{X} 2$ & .254 & .094 & .253 & 2.712 & .009 & .754 & 1.326 \\
\hline & $\mathrm{X} 3$ & .239 & .119 & .198 & 2.011 & .049 & .673 & 1.485 \\
\hline & $\mathrm{X} 4$ & .230 & .091 & .254 & 2.523 & .014 & .645 & 1.550 \\
\hline
\end{tabular}

a. Dependent Variable: $Y$

b. Dependent Variable: RES2

Sumber: Data yang diolah, 2020

Berdasarkan tabel 2 di atas terlihat bahwa nilai dignifikan semua variabel independen $>0,05$, yaitu ditunjukan dengan nilai signifikan untuk kepemimpinan $\left(\mathrm{X}_{1}\right)$ sebesar $0,175>0,05$, lingkungan kerja $\left(\mathrm{X}_{2}\right)$ sebesar $0,284>0,05$, disiplin kerja $\left(\mathrm{X}_{3}\right)$ sebesar $0,126>0,05$ dan motivasi kerja sebesar 0,586>0,05. Sehingga dapat ditarik simpulan model persamaan regresi di variabel kepemimpinnan $\left(\mathrm{X}_{1}\right)$, lingkunngan kerja $\left(\mathrm{X}_{2}\right)$, disiplin kerja $\left(\mathrm{X}_{3}\right)$ dan motivasi kerja $\left(\mathrm{X}_{4}\right)$ tidak terdapat indikasi heteroskedastisitas dan dapat digunakan dalam penelitian ini.

\section{Uji Hipotesis}

\section{a. Analisis Regressi Linier Berganda}

Berdasarkan hasil uji yang menggunakan SPSS 22 diperoleh nilai berikut ini:

$Y=-4,084+0,428 X_{1}+0,254 X_{2}+0,239 X_{3}+0,230 X_{4}$ 
Dengan hasil persamaan regresi tersebut dapat disimpulkan:

1) $\mathrm{a}=-4,084$ artinya bahwa rata-rata kontribusi variable lain yang tidak masuk dalam model memberikan dampak negative terhadap kinerja karyawan.

2) $b_{1}=0,428$ artinya jika skor kepemimpinan meningkat 1 poin, maka kinerja kayawan akan meningkat sebesar 0,428, dengan asumsi lingkungaan kerja, dissiplin kerja dan motvasi kerja dianggap tetap.

3) $b_{2}=0,254$ artinya jika skor lingkungan kerja meningkat 1 poin, maka kinerja kayawan akan meningkat sebesar 0,254, dengan asumsi kepemimpinn, dissiplin kerja dan mtivasi kerja dianggap tetap.

4) $b_{3}=0,239$ artinya jika skor disiplin kerja meningkat 1 poin, maka kinerja kayawan akan meningkat sebesar 0,239, dengan asumsi kepemimpinn, lingkungaan kerja dan motvasi kerja dianggap tetap.

5) $\mathrm{b}_{4}=0,230$ artinya jika skor motivasi kerja meningkat 1 poin, maka kinerja kayawan akan meningkat sebesar 0,230, dengan asumsi kepemimpinn, lingkungaan kerja dan dissiplin kerja dianggap tetap.

\section{b. Uji t}

Uji statistik ini bertujuan untuk menunjukan besar kecilnya efek variabel bebas secara individual dalam mempengaruhi variabel terikat yang diuji pada tingkat signifikansi harus lebih renbdah dari 0,05. Hasil analisis uji t dengan menggunakan SPSS 22 sebagai berikut:

Tabel 3.

Perhitungan Uji t

Coefficients $^{\mathrm{a}}$

\begin{tabular}{|c|c|c|c|c|c|c|}
\hline \multirow{2}{*}{\multicolumn{2}{|c|}{ Model }} & \multicolumn{2}{|c|}{$\begin{array}{c}\text { Unstandardized } \\
\text { Coefficients }\end{array}$} & \multirow{2}{*}{$\begin{array}{c}\text { Standardized } \\
\text { Coefficients }\end{array}$} & \multirow[b]{2}{*}{$\mathrm{t}$} & \multirow[b]{2}{*}{ Sig. } \\
\hline & & $\mathrm{B}$ & Std. Error & & & \\
\hline \multirow[t]{5}{*}{1} & (Constant) & -4.084 & 3.162 & & -1.292 & .202 \\
\hline & $\mathrm{X} 1$ & .428 & .095 & .405 & 4.487 & .000 \\
\hline & $\mathrm{X} 2$ & .254 & .094 & .253 & 2.712 & .009 \\
\hline & $\mathrm{X} 3$ & .239 & .119 & .198 & 2.011 & .049 \\
\hline & $\mathrm{X} 4$ & .230 & .091. & .254 & 2.523 & .014 \\
\hline
\end{tabular}

Sumber: Data yang diolah, 2020

Dengan hasil diatas sehingga dapat diinterpretasikan sebagai berikut: 
1) Pengaruh kepemimpinan terhadap kinerja karyawan. Hasil analisis didapatkan hasil signifikansi variable kepemimpinan $\left(\mathrm{X}_{1}\right)$ adalah 0,000 menunjukan bahwa signifikansi adalah lebih rendah darui 0,05; nilai $t_{\text {hitung }}$ adala 4,487>2,003. Hasil ini berarti bahwa hipotesis 1 adalah kepemimpinan $\mathrm{H} 0$ ditolak dan $\mathrm{Ha}$ diterima. Dengan demikian hal ini menunjukan hipotesis 1 menyatakan kepemimpinnan memiliki pengaruh positif dan signifikan pada kinerja karyawan adalah terbukti kebenarannya.

2) Pengaruh lingkkungan kerja terhdap kineerja karyawan. Hasil analisa data didapatkan nilai signifikansi variable lingkugan kerja $\left(\mathrm{X}_{2}\right)$ adalah sebesar 0,009 menunjukan signifikansi lebih rendah dari 0,05 ; nilai $t_{\text {hitung }}$ adalah $2,712>2,003$. Hasil ini berati hipotesis 2 adalah lingkungan kerja H0 ditolk sedangka Ha diterima. Dengan demikian hal ini menunjukan hipotesis 2 menyatakan lingkungan krja memiliki pengaruh positif dan signifikan terhadap knerja karyawan adalah terbukti kebenarannya.

3) Pengaruh dissiplin kerja terhdap kinrja karyawan. Hasil analisa data didapatkan nilai signifikansi variable disiplin kerja $\left(\mathrm{X}_{3}\right)$ adalah sebesar 0,049 menunjukan signifikansi lebih rendah dari 0,05; nilai $t_{\text {hitung }}$ adalah $2,011>2,003$. Hasil ini berati hipotesis 3 adalah dissiplin kerja H0 ditolaak sedangka Ha diterima. Dengan demikian hal ini menunjukan hipotesis 3 menyatakan disiplin krja memiliki pegaruh positif dan signifikan terhadap knerja karyawan adalah terbukti kebenarannya.

4) Pengaruh motivassi terhdap kinrja karyawan. Hasil analisa data didapatkan nilai signifikansi variable motivasi $\left(\mathrm{X}_{4}\right)$ adalah sebesar 0,014 menunjukan signifikansi lebih rendah dari 0,05 ; nilai $t_{\text {hitung }}$ adalah $2,523>2,003$. Hasil ini berati hipotesis 4 adalah motivasi kerja H0 ditolaak sedangka Ha diterima. Dengan demikian hal ini menunjukan hipotesis 4 menyatakan motivasi 
krja memiliki pegaruh positif dan signifikan terhadap knerja karyawan adalah terbukti kebenarannya.

\section{c. Uji Simultaan (Uji F)}

Pengujian hipotesis secara simultan bertujuan untuk mengukur besarnya pengaruh variabel bebas secara simultan pada variabel terikat. Hasil hipotesis dalam pengujian ini adalah:

Tabel 4

Hasil Uji Sgnifikan Simultan (Uji Statistik) ANOVA ${ }^{\mathrm{a}}$

\begin{tabular}{|ll|r|r|r|r|c|}
\hline \multicolumn{2}{|c|}{ Model } & Sum of & & Mean & & \\
Squares & Df & Square & F & Sig. \\
\hline 1 & Regression & 222.372 & 4 & 55.593 & 23.884 & $.000^{\mathrm{b}}$ \\
& Residual & 132.676 & 57 & 2.328 & & \\
& Total & 355.048 & 61 & & & \\
\hline
\end{tabular}

a. Dependent Variable: Y

b. Predictors: (Constant), X4, X2, X1, X3

Sumber: Daya yang diolah, 2020

Perhitungan tabel 4 diperoleh signifikansi sebesar 0,000 . Dengan menggunakan tingkat signifikansi 0,05 maka nilai signifikansi F sebesar 0,000 menunjukkan lebih rendah dari $0,05(0,000<0,05)$ dan nilai $\mathrm{F}$ hitung 23,884 $>2,53$. Dengan demikian $\mathrm{H} 0$ ditlak dan $\mathrm{Ha}$ diterrima, sehingga hipotesis yang menyebutkan pengaruh signifikan antara variabel bebas kepemimpnan, lingkngan kerja, dissiplin kerja dan motivasi kerja secara bersam-sama terhdap variabel terikat kineerja karyawan (Y) dapat diterima.

\section{d. Koefisien Determinasi $\left(\mathbf{R}^{2}\right)$}

Koefisien determinasi dimaksudkan guna menentukan bersar kecilmya kemampuan variabel bebas untuk menjelaskan variabel terikat. Hasil uji koefisien determinasi dapat ditampilkan pada tabel di awah ini: 
Tabel 5

Hasil Uji Koefisien Determinasi

\begin{tabular}{|l|r|r|r|c|}
\hline Model & R & R Square & Adjusted R Square & $\begin{array}{c}\text { Std. Error of the } \\
\text { Estimate }\end{array}$ \\
\hline 1 & $.791^{\mathrm{a}}$ & .626 & .600 & 1.526 \\
\hline
\end{tabular}

a. Predictors: (Constant), X4, X2, X1, X3

b. Dependent Variable: Y

Sumber: Data yang diolah, 2020

Terlihat pada tabel 5 di atas, angka Adjusted R Square adalah 0,626. Hal ini berarti $62,6 \%$ variabel dependen kinerja mampu dinyatakan variable bebas kepemimpnan, lingkunggan kerja, dissiplin kerja dan motivassi kerja. Sedangkan sisanya $(100 \%-62,6 \%=37,4 \%$ dinyatakan variable lainny yang tidak termasuk dalam penelitian ini, seperti budaya organisasi dan kompetensi.

\section{HASIL DAN PEMBAHASAN}

1. Pengaruh kepemimpnan terhadap kinerja

Pengujian hipotesis terhadap kepemimpinan memperoleh nilai $t_{\text {hitung }}>$ $\mathrm{t}_{\text {tabel }}(4,487>2,003)$ dengan $\mathrm{P}<0,05$ hasil ini menyatakan variable kepemimpinan $\mathrm{H} 0$ ditlak sedagkan $\mathrm{H}_{1}$ diterima. Dengan demikian kepemimpinan berpengaruh yang signifikan terhadap kineerja karyawan. Hasil analisa ini menggmbarkan bahwa faktor penguat meningkatnya kinerja karyawan dilihat dari cara seorang pemimpin memimpin para bawahanya dan mampu menginspirasi para pengikutnya, kepemimpinan adalah persoalan sosial yangmana didalamnya terjadi keterkaitan antara pemimpin dengan orng yang dipimpinnya dengan maksud mendapatkan tujuan organisasi, dengan cara mempengaruhi, membujuk, memotivasi dan mengkoordinasi.

Hasil penelitian didukung dengan hasil penelitian Fikri Djafar Fadude, Hendra N. Tawas, Jane Grace Poluan (2019), Alwi Suddin, Sudarman (2010), Asta Wijayan, Alwi Suddin, SL. Triyaningsih, (2016) dan Maria R. Kustrianingsih, Maria M. Minarsih, Leonardo Budi Hasiolan (2016) bahwa secara parsial variabel kepemimpinan memiliki pengaru positif dan signifikan pada kinerja karyawan. 
2. Pengaruh lingkungn kerja pada kinerja

Pengujian hipotesis terhadap lingkungan kerja memperoleh nilai $t_{\text {hitung }}$ $>\mathrm{t}_{\text {tabel }}(2,712>2,003)$ dengan $\mathrm{P}<0,05$ hasil analisis ini berarti bahwa variabl lingkungan kerja $\mathrm{H} 0$ ditolak dan $\mathrm{H}_{2}$ diterima. Dengan demikian lingkungan kerja berpengaruh yang signfikan pada kinerja karyawan. Maka diinterpretasikan bahwa lingkngan kerja merupakan suatu keadaan yang memiliki pengaruh terhadap jalannya operasi perusahaan. Berdasarkan definisi diatas maka lingkungan kerja adalah kondisi yang berada di antara pekerja yang ampu memberi pengaruh pada kinerja. Semakin membaiknya sebuah lingkungan kerja, maka akan semakin meninggkat kinerja dalam sebuah perusahaan, organisasi ataupun instansi.

Hasil penelitian didukung dengan hasil penelitian Joyce Sagita Noviyanti (2015), Alwi Suddin, Sudarman (2010), Heny Sidanti (2015) dan Asta Wijayan, Alwi Suddin, SL. Triyaningsih (2016) bahwa secara parsial variabel ligkungan kerja memiliki pengaruh positif dan signifikan pada kinerja.

3. Pengaruh disiplin kerja pada kinerja

Pengujian hipotesis terhadap disiplin kerja memperoleh nilai $t_{\text {hitung }}>$ $\mathrm{t}_{\text {tabel }}(2,011>2,003)$ dengan $\mathrm{P}<0,05$ kondisi ini menyatakan bahwa variable disiplin kerja $\mathrm{H} 0$ ditolak dan $\mathrm{H}_{3}$ diterima. Dengan demikian disiplin kerja berpengaruh signifikan pada kinerja. Disiplin kerja adalah perilaku pegawai yang menampakkan sikap taat, patuh, setia, teratur dan tertib pada tatatertib organisasi yang berlaku. Disiiplin kerja yang tinggi memberi jaminan tertibnya suasana kerja dan kerja perusahaan menjadi lancar sehingga perusahaan mampu mencapai hasil opotimal. Disiplin kerja bagi karyawan memberikan pengaruh pada suasana kerja yang menggembirakan yang akhirnya semangat pegawai dalam mengerakan pekerjannya meningkat. Jadi semakin ditingkatkan disiplin maka kinerja juga akan meningkat.

Hasil penelitian didukung dengan hasil penelitian Joyce Sagita Noviyanti (2015), Heny Sidanti (2015), Natalia Susanto (2019) dan Asta 
Wijayan, Alwi Suddin, SL. Triyaningsih (2016) bahwa secara parsial variabel dissiplin kerja emiliki pengaruh positif serta signifikan pada kinerja.

4. Pengaruh motivasi pada kinerja

Pengujian hipotesis terhadap motivasi kerja memperoleh nilai $t_{\text {hitung }}>$ $\mathrm{t}_{\text {tabel }}(2,523>2,003)$ dengan $\mathrm{P}<0,05$ kondisi ini enggambarkan variable motivasi $\mathrm{H} 0$ ditolak dan $\mathrm{H}_{4}$ diterima. Dengan demikian motivasi kerja berpengaruh yang signfikan pada kinerja. Hal ini dapat diinterpretasikan bahwa dengan adanya motivasi yang baik dalam bekerja akan memperoleh kinerja karyawan yang maksimal sedangkan dengan motivasi yang kurang akan menghasilkan kinerja karyawan yang rendah.

Hasil penelitian didukung dengan hasil penelitian Joyce Sagita Noviyanti (2015), Alwi Suddin Sudarman (2010), Heny Sidanti (2015), Natalia Susanto (2019) dan Maria R. Kustrianingsih, Maria M. Minarsih, Leonardo Budi Hasiolan (2016) bahwa secara parsial variabel motivasi memiliki pengaruh possitif dan signifikan pada kinerja.

\section{KESIMPULAN}

Berdasarkan hasil penelitian dari pembahasan yang telah dilakukan maka dapat disimpulkan sebagai berikut:

1. Kepemimpinan secara parsial memiliki pengaruh positif serta signifikan pada kinerja karyawan pada Dinas Peternakan dan Perikanan Kabupaten Grobogan.

2. Lingkungan kerja secara parsial memiliki pengaruh positif serta signifikan pada kinerja karyawan Dinas Peternakan dan Perikanan Kab. Grobogan.

3. Disiplin kerja secara parsial memiliki pengaruh positif serta signifikan pada kinerja karyawan pada Dinas Peternakan dan Perikanan Kab. Grobogan.

4. Motivasi kerja secara parsial memiliki pengaruh positif serta signifikan pada kinerja karyawan Dinas Peternakan dan Perikanan Kab. Grobogan.

5. Secara silmultan kepemimpinan, lingkungan kerja, disiplin kerja dan motivasi kerja memiliki pengaruh positif serta signifikan pada kinerja karyawan Dinas Peternakan dan Perikanan Kab. Grobogan.

6. Hasil koefisien determinasi diperoleh nilai Adjusted $R^{2}$ sebesar 0,626 atau sebesar 62,6\% menunjukan bahwa kinersja karyawan Dinass Peternakan dan 
Perikanan Kab. Grobogan dipengaruhi oleh variabel kepeimpinan, lingkngan kerja, displin kerja dan motiivasi kerja, sedangkan sisanya 37,4\% dijelaskan oleh variabel-variabel lain yangtidak termasuk dalam penelitian ini seperti budaya organisasi dan kompetensi.

\section{DAFTAR PUSTAKA}

Adinda Citra DyahNingrumsari, 2020. Pengaruh Kepemimpinan, Lingkungan Kerja, Disiplin Kerja Terhadap Kinerja Karyawan PT. Dutacipta Pakar Perkasa Surabaya. Jurnal Manajemen 2 (2).

Alwi Suddin, Sudarman. 2010. Pengaruh Kepemimpinan, Motivasi, Dan Lingkungan Kerja Terhadap Kinerja Pegawai Kecamatan Laweyan Kota Surakarta. Jurnal Manajemen Sumberdaya Manusia, 4 (1), 1-8.

Any Isvandiari, Bagus Al Idris, 2018. Pengaruh Kepemimpinan Dan Disiplin Kerja Terhadap Kinerja Karyawan Pada PT Centra Capital Futures Cabang Malang. Jurnal Ilmiah Bisnis dan Ekonomi 12 (1), 17-22.

Asmara Indahingwati, Rahman Al Hafidz, 2020. Pengaruh Kepemimpinan, Motivasi Kerja Dan Disiplin Kerja Terhadap Kinerja Guru MI Tarbiyatus Syarifah. E-Jurnal SPIRIT PRO PATRIA 6 (1), 36-50

Asta Wijayan, Alwi Suddin dan SL Triyaningsih. 2016. Pengaruh Kepemimpinan, Lingkungan Kerja, Kompetensi, dan Disiplin Kerja Terhadap Kinerja Guru SMP PGRI 6 Kedawung Sragen. Jurnal Manajemen Sumber Daya Manusia, 10 (1), 95-105.

Dedy Mulyadi, Amanda Syafitri, 2015. Pengaruh Kepemimpinan Dan Motivasi Kerja Terhadap Kinerja Karyawan di Bank BJB Syariah Cabang Bogor. Jurnal Ilmiah Binaniaga, 11 (2).

Deni Candra Purba, Victor P.K Lengkong dan Sjendry Loindong. 2019. Analisis Pengaruh Kepuasan Kerja, Motivasi Kerja dan Disiplin Kerja Terhadap Kinerja Karyawan Pada Perusahaan Umum Percetakan Negara Republik Indonesia Cabang Manado. Jurnal EMBA, 7 (1), 841-850.

Fikri Djafar Fadude, Hendra N. Tawas dan Jane Grace Poluan.2019. Pengaruh Kepemimpinan, Budaya Organisasi, dan Kompetensi Terhadap Kinerja Karyawan PT. Bank Syariah Mandiri Cabang Bitung. Jurnal Emba, 7 (1), 31-40.

Heny Sidanti.2015. Pengaruh Lingkungan Kerja, Disiplin Kerja dan Motivasi Kerja Terhadap Kinerja Pegawai Negeri Sipil di Sekretariat Kabupaten Madiun. Jurnal JIBEKA, 9 (1), 44-53. 
Joyce Sagita Noviyanti. 2015. Pengaruh Motivasi Kerja, Lingkungan Kerja dan Disiplin Kerja Terhadap Kinerja Pegawai pada BAPPEDA Provinsi Sulawesi Tengah. Jurnal Katalogis, 3 (1), 105-115.

Jurnalprodi.Idu.ac.id > aeticle - Pengaruh lingkungan kerja, kesejahteraan dan kepemimpinan terhadap motivasi kerja prajurit pengawak KRI di SATKOR KOARMATIM

Maria Rini Kustrianingsih, Maria Magdalena Minarsih dan Leonardo Budi Hasiolan. 2016. Pengaruh Motivasi Kerja, Kepemimpinan dan Iklim Organisasi Terhadap Kinerja Karyawan Pada Dinas Kebudayaan dan Pariwisata Kota Semarang, Jurnal Of Management, 2 (2).

Natalia Susanto, 2019. Pengaruh Motivasi Kerja, Kepuasan Kerja, Dan Disiplin Kerja Terhadap Kinerja Karyawan Pada Divisi Penjualan PT REMBAKA. AGORA, 7 (1).

Sugiyono. 2008. Metode Penelitian Bisnis. Bandung: Alfabeta 